Marquette University

e-Publications@Marquette

$9-2016$

\title{
Triangulation and Parent-Adolescent Relationships: Implications for Adolescent Dating Competence and Abuse
}

Gregory M. Fosco

Marquette University

Mengya Xia

The Pennsylvania State University

Mark G. Lynn

Northwestern University

John H. Grych

Marquette University, john.grych@marquette.edu

Follow this and additional works at: https://epublications.marquette.edu/psych_fac

Part of the Psychology Commons

\section{Recommended Citation}

Fosco, Gregory M.; Xia, Mengya; Lynn, Mark G.; and Grych, John H., "Triangulation and Parent-Adolescent Relationships: Implications for Adolescent Dating Competence and Abuse" (2016). Psychology Faculty Research and Publications. 256.

https://epublications.marquette.edu/psych_fac/256 
Marquette University

e-Publications@Marquette

\section{Psychology Faculty Research and Publications/College of Arts and Sciences}

This paper is NOT THE PUBLISHED VERSION.

Access the published version at the link in the citation below.

Journal of Research on Adolescence, Vol. 26, No. 3 (September 2016): 524-537. DOI. This article is (C) Wiley and permission has been granted for this version to appear in e-Publications@Marquette. Wiley does not grant permission for this article to be further copied/distributed or hosted elsewhere without the express permission from Wiley.

\section{Triangulation and Parent-Adolescent Relationships: Implications for Adolescent Dating Competence and Abuse.}

Gregory M. Fosco

Department of Psychology, Pennsylvania State University, University Park, PA 16802, U.S.A.

Mengya Xia

Department of Psychology, Pennsylvania State University, University Park, PA 16802, U.S.A.

Mark G. Lynn

Department of Psychology, Northwestern University, Evanston, IL 60208, U.S.A.

John H. Grych

Department of Psychology, Marquette University, Milwaukee, WI 53233, U.S.A.

\section{Abstract}

This study focuses on family predictors of conflict behavior in adolescent dating relationships, drawing on family systems and socialization perspectives. Mother-adolescent, father-adolescent, and triadic relationships each was examined as predictors of adolescent dating outcomes that hold importance for 
developmental and prevention science (positive conflict resolution, verbal abuse, and physical abuse). We conducted a longitudinal analysis using a 6-month longitudinal design with 236 ethnically diverse high school students. Findings indicate that triangulation into parental conflicts was related to increases in positive conflict resolution and with increases in verbally abusive behavior with dating partners over time. Parent-adolescent closeness and conflict each was related to positive conflict resolution and verbal abuse, but these associations were only found for boys.

\section{Introduction}

Adolescent dating relationships have important developmental implications across several domains. Adolescents report that having a dating partner and the quality of their dating relationships are associated with their popularity with their peers (Simon, Aikins, \& Prinstein, [59]), with their psychological adjustment (Davies \& Windle, [21]), and with their academic success and future orientation (Furman \& Collins, [30]). In addition, the conflict resolution strategies learned in adolescent dating relationships set the foundation for later significant relationship competence (Seiffge-Krenke, [58]) as well as sexual, behavioral, and emotional health (Aikins, Simon, \& Prinstein, [3]). Thus, it is important to examine multiple aspects of adolescent dating relationships that place them at risk or promote adaptive functioning in later relationships.

Abusive behavior is a risk factor that is remarkably common in adolescent dating relationships. For example, physical violence, such as pushing, slapping, kicking, or punching one's dating partner, is endorsed by $15 \%-40 \%$ of adolescents in dating relationships (Foshee, [28]; O'Leary, Smith Slep, AveryLeaf, \& Cascardi, [51]). Verbally abusive behavior is even more common. Dating violence has profound implications for adolescent well-being, with those in violent relationships at higher risk for injuries that require medical attention from a physician (O'Leary et al., [51]) as well as emotional distress, trauma, and substance use (Ackard, Eisenberg, \& Neumark-Sztainer, [1]; Callahan, Tolman, \& Saunders, [13]; Jouriles, McDonald, Garrido, Rosenfield, \& Brown, [40]). Less is known about adolescents' dating relationship competence, which draws attention to adolescents' ability to skillfully engage in interpersonal interactions, such as effective problem solving, that can promote satisfying and positive relationships (Davila, Stroud, Miller, \& Steinberg, [22]). Effective communication and problem-solving skills are viewed as core aspects of relationships that are characterized by equality and a lack of power assertion (Creasey \& Hesson-McInnis, [17]; Tuval-Mashiach \& Shulman, [64]). Even further, adolescent dating violence prevention programs target the development of effective conflict resolution strategies to reduce risk for relationship abuse and the associated maladjustment (for a review see Cornelius \& Resseguie, [16]).

Recognition of the developmental significance of adolescent dating relationships has led to growing interest in identifying and understanding the determinants of adolescent dating aggression and competence (Collins, Welsh, \& Furman, [14]). Many studies have focused on the family context as a critical "forerunner" to adolescent dating violence perpetration (Jouriles, McDonald, Mueller, \& Grych, [41]). The social-interactional context of the family teaches children and adolescents appropriate ways of managing their emotions and behavior in family interactions, which then generalizes to other interpersonal interactions (Eisenberg, Cumberland, \& Spinrad, [25]; Grusec, [32]; Halberstadt, [36]). Much of this research has focused on parent-child interactions as playing a central role in teaching children and adolescents' social skills and appropriate ways of navigating conflicts (Grusec, [32]). 
However, the family context is comprised of a multitude of relationships that are interdependent and each may be influential in the development of adolescents' interpersonal repertoire (Minuchin, [50]). Integrating parent-adolescent relationships and broader family dynamics may help provide greater insight into interpersonal experiences that inform socialization outcomes. In this study, we examine parent-adolescent relationship quality and consider the unique implications of adolescent involvement in interparental conflict as a socializing process that may contribute to adolescents' dating relationships.

\section{The Parent-Adolescent Relationship and Adolescent Dating Relationships}

The parent-child relationship has an important role in socializing self-regulation and interpersonal skills (Grusec, [32]), which in turn underlie adolescents' developing ability to effectively handle conflict with significant others (Grych \& Kinsfogel, [33]; Kinsfogel \& Grych, [43]). One key domain of parentadolescent relationships is closeness. There is a wealth of evidence linking supportive, trusting parentadolescent relationships and positive psychological development; moreover, relationship closeness is a more stable influence through childhood and adolescence than aspects of parental control that change over developmental transitions (Hill, Bromell, Tyson, \& Flint, [37]). Close relationships promote communication and disclosure with parents, creating the opportunity for parental guidance and support around decision making related to risky behavior (Vieno, Nation, Pastore, \& Santinello, [65]). Moreover, adolescents who experience effective communication and emotional closeness with their parents gain important interpersonal and conflict resolution skills that help to reduce the likelihood of violent acts in dating relationships (Cui \& Conger, [18]) and improve the quality of early-adult romantic relationships (Simpson, Collins, Tran, \& Haydon, [61]).

Parent-adolescent aggression is another family influence on adolescent dating relationship violence (Buehler, [10]; Linder \& Collins, [46]; Meeus, Branje, Van Der Valk, \& de Wied, [48]). Research on coercive family processes has consistently found that parents' aggressive and domineering tactics are often indicative of a reciprocal dynamic of escalating hostility between parent and child that typically involves interactional contingencies, which in turn reinforce their child's aggressive behaviors (Patterson, [52]; Patterson, Reid, \& Dishion, [54]). Children's aggressive behavior toward others becomes internalized due to repeated reinforcement from coercive family interactions, serving as a kind of "basic training" in aggressive behavior toward others (Granic \& Patterson, [31]; Patterson, DeBaryshe, \& Ramsey, [53]). From this social-interactional perspective, repeated experiences of parental aggression may lead adolescents to develop an interpersonal template for conflict resolution that surfaces in their dating relationships. Parents' provision of poor models of conflict resolution and the perpetuation of parent-child conflict are associated with adolescents' inclination to make poor peer and dating relationship choices (Brown, Mounts, Lamborn, \& Steinberg, [8]; Scaramella, Rand, Conger, Spoth, \& Simons, [56]; Simons, Chao, Conger, \& Elder, [60]). This body of research converges in the prediction that parent-adolescent aggression is a robust and important risk factor for poor conflict resolution in other relationships.

\section{Triangulation Into Parental Conflicts and Adolescent Dating Relationships}

Focusing entirely on parent-adolescent dyads may present too narrow of a view of the family socialization of adolescent dating behaviors and may overlook other family dynamics that shape adolescents' conflict resolution skills. Adolescents can become direct participants in their parents' 
conflicts, a process generally referred to as triangulation. Triangulation can take different forms, including distracting parents from their arguments, forming alliances with one parent against the other, or even serving as a mediator in parental disputes (Buchanan \& Waizenhofer, [9]; Minuchin, [49]). In general, triangulation is a risk factor associated with poorer adolescent well-being and selfesteem (Fosco \& Grych, [26]; Grych, Raynor, \& Fosco, [34]; Jacobvitz \& Bush, [38]; Wang \& Crane, [66]), and also undermines adolescents' relationships with their parents (Afifi \& Schrodt, [2]; Amato \& Afifi, [4]; Fosco \& Grych, [27]). Beyond risk for poorer psychosocial outcomes and parent-adolescent relationships, little is known about how triangulation might impact adolescent's behaviors in other relationships. Yet, triangulation may provide a unique experience relevant to resolving conflicts. Typically, adolescents are triangulated into parental conflicts in the context of an ailing marriage, typically characterized by ineffective communication and problem-solving skills (Bell, Bell, \& Nakata, [6]; Minuchin, [49]). It is possible that adolescent involvement in parental conflicts may facilitate the development of either conflict resolution skills or deficits (Jacobvitz \& Hazen, [39]). On one hand, adolescents who successfully mediate parental disputes may learn effective conflict resolution skills. On the other hand, adolescents who are caught in the middle of dysfunctional family processes may learn maladaptive methods for managing discord. For example, youth may develop patterns of emotional reactivity to parental conflicts that also surface in friendships and dating relationships, undermining their quality (Cook, Buehler, \& Blair, [15]).

The handful of studies investigating links between adolescent triangulation and peer relationships supports the latter possibility. For example, young children who report stronger cross-generational coalitions are more likely to be rated by their teachers as having problematic peer relationships (Leon, Wallace, \& Rudy, [44]). Buehler, Franck, and Cook ([11]) report longitudinal findings for the negative impact of triangulation on early adolescents' perceptions of peer rejection and peer support 2-3 years later. Finally, one study drawing on an undergraduate sample of young women found that parentdaughter boundary dissolution was associated with inhibited exploration in young women's friendships and romantic relationships (Fullinwinder-Bush \& Jacobvitz, [29]). However, there have not been any studies that examine associations between triangulation and conflict resolution in adolescent dating relationships. Adolescent involvement in parental conflicts may play an important socialization role that can inform how they manage conflict in their own dating relationships. Consistent with evidence linking triangulation and poor peer relationship outcomes, we expect that triangulation may be a risk factor for more hostile, abusive adolescent dating behaviors.

\section{The Moderating Role of Adolescent Gender}

There are differences that emerge in the association between parent-adolescent relationships and adolescent dating relationships. For example, Grych and Kinsfogel ([33]) found gender differences in the associations among family conflict, high school boys' and girls' attachment style, and abusive dating behavior. Other findings indicate that there are distinct pathways to dating violence for boys and girls (Kinsfogel \& Grych, [43]). Taken together, these studies indicate that it is important to examine the role of adolescent gender to gain a clearer understanding of how families contribute to adolescent dating aggression and competence (McKinney \& Renk, [47]).

Adolescent gender differences in the effects of triangulation are less consistent. There is some evidence that girls are more affected by triangulation into conflicts than boys, which may indicate that 
girls are more sensitive to relational dynamics inherent in family processes around parental conflict (Jacobvitz \& Bush, [38]). However, in a study using diary methods, parents indicated that adolescent boys were more likely to become involved in parental conflicts than adolescent girls (Cummings, Goeke-Morey, Papp, \& Dukewich, [19]). More recent studies have failed to find any support for the moderating role of adolescent gender on the relationship between triangulation and adjustment (Buehler \& Welsh, [12]) or peer relations (Buehler et al., [11]). Given the inconsistent evidence, the role gender plays in the link between triangulation and interpersonal relationships remains an open question that warrants continued exploration.

\section{The Current Study}

Guided by family systems and socialization frameworks, we examined parent-adolescent relationships and adolescent triangulation into parental conflicts as distinct predictors of adolescents' physical abuse, verbal abuse, and positive conflict resolution behaviors in dating relationships. Because triangulation occurs more frequently in discordant marriages, it was important to control for levels of interparental conflict in families, consistent with other work linking triangulation with peer relations (Buehler et al., [11]) to help disentangle the distinct effects of triangulation on adolescent dating behavior.

In this study, we employed a short-term longitudinal design to examine whether parent-adolescent relationship quality and triangulation were uniquely related to changes in adolescent dating relationship behaviors over time, and whether these associations were moderated by adolescents' gender. First, we examined parent-adolescent closeness and adolescent triangulation as predictors of adolescent dating outcomes. We hypothesized that parent-adolescent closeness would be related to more positive dating relationships, characterized by better conflict resolution skills and less frequent verbal and physical abuse. We also hypothesized that triangulation would be associated with less positive conflict resolution skills and more abusive behaviors. Second, we examined the role of parentadolescent conflict and triangulation as risk factors for adolescent dating behavior problems. In addition to previously stated hypotheses, we also predicted that frequent parent-adolescent hostility would be related to less constructive conflict resolution and more abusive behavior in dating relationships. In addition, we evaluated the interactive effects of triangulation and parent-adolescent relations and the role of gender as a moderator of family relationships on dating relationship outcomes. No specific hypotheses were set for these interactions due to the exploratory nature of the analyses. Across both sets of analyses, we controlled for adolescent gender and age. In addition, we included adolescent anger regulation as a statistical control to account for tendencies to become angry and difficulties with regulating one's anger. These covariates were included to provide a more conservative test of triangulation and parent-adolescent relationships in relation to dating relationship behaviors.

\section{Method}

\section{Participants and Procedures}

Participants were recruited from a large, ethnically diverse urban public high school in the upper Midwest. Letters explaining the study and consent forms were sent home to parents of students who were enrolled in social studies classes; $80 \%$ of parents gave permission for youth participation. 
Adolescents who obtained parents' informed consent were invited to participate, and approximately $75 \%$ of those students were present on the day of the collection and agreed to complete the survey packet. Data collection took place during 90-min social studies class periods, with two researchers present to answer any questions individually during administration; however, only research assistants collected surveys upon completion. Those who had not obtained parental consent were excused and given an alternate activity to complete in a different location. Adolescents' signed consent was then obtained, and questionnaires were distributed with the instructions to complete them quietly and without conversing with their peers. This resulted in a total sample of 326 ninth- through twelfth-grade students. The majority (72.3\%) reported that they were currently dating someone or had been dating someone within the last 3 months. This subsample $(n=236)$ was used for analysis in the study. Adolescents in this subsample were $60.6 \%$ female, 14 to 19 years old ( $M=16.38, S D=1.17$ ), $56.8 \%$ Caucasian, 14.0\% African American, 18.6\% Latino/Hispanic, 3.4\% Asian/Pacific Islander, 2.5\% Native American, $2.5 \%$ biracial, and $2.1 \%$ other; $48.3 \%$ reported their parents were divorced. In the analyzed subsample, $84 \%$ reported living with their mother, 55\% reported living with their father, $9 \%$ reported living with a stepmother, $2 \%$ reported living with a stepfather, $4 \%$ reported living with another relative, and $2 \%$ reported living with another adult. No information on socioeconomic status (SES) was collected from the participants. Participants were instructed to respond to questionnaires about interparental conflict or parent-child relationships in a manner reflective of their family circumstances.

The second data collection (T2) occurred approximately six months later. At that time, students were enrolled in different classes than at T1, which made it impossible to distribute the questionnaire packets to the same groups that had completed them at T1. Instead, all T1 participants were excused from their third-period class and invited to fill out the packets in the lunchroom at the same time. Many T1 participants either were absent from school that day, failed to receive the message to go to the lunchroom, or failed to make it to the lunchroom after leaving their class. As a result, 106 students, $44.9 \%$ of the T1 subsample, completed the T2 assessment; $94 \%$ of this subsample were in a relationship at that time. Because of this rate of attrition, we conducted analyses to identify patterns of missing data for the variables of interest. A Little's missing completely at random (MCAR) test revealed there were nonrandom patterns of missingness, $\chi^{2}(204)=272.47, p<.01$. We conducted a series of t-tests for all T1 predictors and covariates to determine whether there were differences for those who were present or not present at T2. In addition, we also tested for differences in internalizing and externalizing problems at T1. Differences emerged for two variables. Adolescents who were older at $\mathrm{T} 1$ were more likely to have missing data at $\mathrm{T} 2, \mathrm{t}(232)=2.64, \mathrm{p}<.01$. Adolescents with a lower GPA at $\mathrm{T} 1$ also were more likely to have missing data at $\mathrm{T} 2, \mathrm{t}(232)=2.64, \mathrm{p}<.01$. Chi-square tests revealed no differences in adolescent gender or parental divorce status at $\mathrm{T} 2$.

Multiple imputation (MI) was used to minimize potential bias incurred by missing data. Twenty imputed data sets were created using relevant variables that were either correlated with the likelihood that individuals were missing at T2 (i.e., GPA), or because they contributed to the overall predictive model for estimating missing data (e.g., verbal abuse at T1) and reducing likelihood of bias in our multivariate analyses (Schlomer, Bauman, \& Card, [57]; Widaman, [68]). 


\section{Measures}

\section{Interparental conflict}

Participants' reports of their parents' conflicts were assessed using the Conflict Properties subscale of the Children's Perception of Interparental Conflict questionnaire (CPIC; Grych, Seid, \& Fincham, [35]). The 19-item Conflict Properties scale assesses the frequency, intensity, and resolution of interparental conflict. Sample statements include "I often see or hear my parents arguing" and "My parents get really mad when they argue" to which children respond on a 3-point scale (true, sort of true, or false). This measure correlates significantly with parental reports of interparental conflict and has demonstrated satisfactory levels of internal consistency and test-retest reliability (Grych et al., [35]). The reliability of the Conflict Properties subscale was ( $\alpha$ 's T1 = .94, T2 = .93) consistent with values reported by Grych et al. ([35]) for children and by Bickham and Fiese ([7]) for adolescents.

\section{Anger regulation}

Adolescents' tendency to experience and express anger was assessed with the Trait Anger Scale (TAS; Spielberger, Jacobs, Russell, \& Crane, [62]). This measure was designed to capture aspects of anger experiences that are fairly stable individual characteristics that differ from the respondent's current mood. The 15 items in this scale were rated on a 4-point scale ranging from 1 (almost never) to 4 (almost always). Sample items include "I have a fiery temper" and "I fly off the handle." This scale had good internal consistency $(\alpha=.86)$.

\section{Triangulation}

Adolescent triangulation into parental conflicts was assessed using the Triangulation subscale of the CPIC (Grych et al., [35]). This 8-item subscale assesses a wide range of triangulation behaviors, capturing the extent to which adolescents feel involved in, caught in the middle of, or drawn into crossgenerational coalitions during their parents' conflict. Sample items include "When my parents argue I end up getting involved somehow" and "I feel caught in the middle when my parents argue." This scale correlates with observed child involvement in interparental conflict during triadic family interactions (Lindahl, [45]). Reliability of the Triangulation subscale was.72 at T1 and.80 at T2.

\section{Closeness with parents}

Adolescents completed the trust and communication scales of the Inventory of Parent and Peer Relationships (IPPA; Armsden \& Greenberg, [5]). These subscales were highly correlated ( $r s=.82-.87$, ps $<.001)$ and thus were combined to create a single scale measuring the quality of adolescent's relationships with their mothers and fathers, labeled closeness. This scale was comprised of 20 items, rated on a 5-point Likert scale ranging from almost never or never to almost always or always and included items such as "my father encourages me to talk about my difficulties" and "I tell my mother about my problems and troubles." Closeness scales demonstrated good internal consistency for mothers and fathers, at T1 ( $\left.\alpha^{\prime} s=.95\right)$ and were moderately correlated $(r=.32, p<.01)$. Following zscore transformations, these scales were averaged together to create a single composite variable for parent-adolescent closeness.

\section{Parent-adolescent conflict}

Adolescents completed the Conflict Tactics Scale-Parent-Child version (CTS-PC, Straus, [63]). Adolescents rated the frequency of conflict behaviors that occurred with their mothers and fathers separately over the past year on a scale ranging from 0 (never) to 6 (more than 20 times). The 12 items 
on this scale ranged from lower levels of parent-adolescent conflict (e.g., "raised voice and yelled at you") to more intense levels of conflict (e.g., "pushed, grabbed, or shoved you"). This measure was reliable for mother-adolescent $(\alpha=.92)$ and father-adolescent $(\alpha=.90)$ conflict. Adolescents' reports of their relationships with their mother and father were correlated $(r=.35, p<.01)$. Following z-score transformations, these scales were averaged together to create a single composite variable for parentadolescent conflict.

\section{Dating relationship behavior}

Consistent with our focus on competence in dating relationships, measurement of dating relationship behaviors focused on the adolescents' behavior toward their dating partners in three domains: positive conflict resolution, verbal abuse, and physical abuse. These were measured using three scales from the Conflict in Adolescent Dating Relationship Inventory (CADRI; Wolfe et al., [69]). Adolescents rated the frequency of their conflict behaviors with their boyfriend/girlfriend in the past year. They were instructed to respond to questions about their current relationship, or, if they were not in a relationship at the time of the assessment, they were asked to respond about their most recent relationship (within the last year). Questions were answered on a 4-point scale: 0 (never), 1 (seldom: this has happened only 1 to 2 times), 2 (sometimes: this has happened about 3 to 5 times), or 3 (often: this has happened 6 times or more). Forms were identical for boys and girls, except that appropriate pronouns were used in questions related to dating relationships. Although students were not asked to report on their sexual orientation in the school-based survey, they were instructed to complete the questionnaires in a manner that was consistent with their sexual orientation.

\section{Positive conflict resolution}

Adolescents responded to the 9-item positive conflict resolution scale. This scale assessed constructive conflict behaviors such as attempts to stay calm during disagreements, perspective taking, and collaborative problem-solving strategies. Sample items include the following: "I discussed the issue calmly," "I offered a solution that I thought would make us both happy," or "I agreed that he (she) was partly right." This scale had adequate reliability at T1 (.70) and T2 (.85).

\section{Verbal abuse}

Adolescents also completed the verbal emotional abuse scale, which assessed the frequency at which they were insulting, belittling, or coercive with their dating partner. Sample items include, "I insulted her (him) with put downs," "I threatened to end the relationship," and "I said things just to make her (him) angry." This 10-item scale had adequate reliability at T1 (.84) and T2 (.86).

\section{Physical abuse}

Adolescents also completed the physical abuse scale, which included four items that assessed the frequency at which they used physical aggression with their dating partner. Items included "I pushed, shoved, or shook her (him)," "I kicked, hit, or punched her (him)," "I slapped her (him) or pulled her (his) hair," and "I threw something at her (him)." This scale had adequate reliability at T1 (.76) and T2 (.86).

\section{Analytic Procedures}

Our analyses proceeded in a sequence of steps. First, we computed correlations and descriptive statistics. Then, we proceeded to compute two sets of hierarchical regression analyses, for each of the 
three outcome variables (positive conflict resolution, verbal abuse, and physical abuse), controlling for T1 levels. Hierarchical regression equations were computed in SAS version 9.3 (SAS, [55]), in each of the 20 imputed data sets. These findings are compiled and are reported as average values for parameter estimates and R-square values. When analyzing imputed data in this way, SAS is only able to compute unstandardized coefficients. Therefore, prior to analysis, we standardized all variables so that unstandardized coefficients would be reported in the metric of standard deviations and could be interpreted as standardized coefficients.

Hierarchical regression equations were computed using three blocks. In the first step, T2 outcome variables were regressed on: (1) main effect variables for T1 outcomes, (2) control variables (adolescent gender, adolescent age, anger regulation, and interparental conflict), and (3) hypothesized predictors (triangulation, and parent-adolescent closeness or conflict). In the second block, we entered two-way interaction terms for triangulation, parent-adolescent relationship quality, and adolescent gender. In the third block, we entered three-way interaction terms to the regression equation. Following these analyses, we plotted statistically significant interaction terms and computed simple slopes for the plotted lines using interaction plotting software (Dawson, [24]) and computed simple slopes for groups, either for boys and girls, or using a \pm .5 SD split for continuous variables.

\section{Results}

Table 1 presents correlations, means, and standard deviations for variables examined in this study. Consistent with the family systems view that family relationships are interdependent, there were consistent correlations among interparental, parent-adolescent, and triadic relationships (i.e., triangulation). Interparental conflict was correlated with more frequent triangulation, and both interparental conflict and triangulation were generally correlated with lower levels of closeness and more frequent parent-adolescent conflicts. 
Table 1. Correlations and Descriptive Statistics

\begin{tabular}{|l|l|l|l|l|l|l|l|l|l|l|l|l|l|}
\hline Variables & 1 & 2 & 3 & 4 & 5 & 6 & 7 & 8 & 9 & 10 & 11 & 12 & 13 \\
\hline 1.Gender & - & & & & & & & & & & & & \\
\hline 2.Age, T1 & .07 & - & & & & & & & & & & \\
\hline 3.IP Conflict, T1 & .02 & -0.05 & - & & & & & & & & & & \\
\hline 4.Anger reg, T1 & -.10 & -0.01 & 0.11 & - & & & & & & & & & \\
\hline 5.Triangulation, T1 & .09 & -0.05 & $0.44^{* *}$ & $0.21^{*}$ & - & & & & & & & & \\
\hline 6.P-A close, T1 & .11 & $-0.16^{*}$ & $-0.32^{*}$ & -0.09 & -0.07 & - & & & & & & & \\
\hline 7.P-A conflict T1 & -.06 & 0.02 & $0.43^{*}$ & $0.22^{*}$ & $0.26^{*}$ & $-.51^{*}$ & - & & & & & & \\
\hline 8.Pos. res., T1 & -.06 & 0.13 & -0.08 & 0.09 & -0.06 & .03 & $-.18^{*}$ & - & & & & & \\
\hline 9.Pos. res., T1 & -.09 & $0.20^{*}$ & -0.06 & -0.04 & 0.14 & $-.26^{*}$ & $0.54^{*}$ & - & & & & & \\
\hline 10.Verb. abuse, T1 & -.02 & $0.17^{*}$ & 0.04 & $0.38^{*}$ & 0.06 & -.13 & .06 & $0.43^{*}$ & 0.16 & - & & & \\
\hline 11.Verb. abuse, T2 & -.18 & $0.24^{*}$ & 0.06 & $0.27^{*}$ & 0.10 & -.18 & .14 & $0.36^{*}$ & $0.30^{*}$ & $0.73^{*}$ & & & \\
\hline 12.Phys. abuse, T1 & $-.19 *$ & 0.11 & 0.09 & $0.20^{*}$ & 0.04 & -.07 & $.16^{*}$ & 0.13 & 0.04 & $0.41^{*}$ & $0.28^{*}$ & & \\
\hline 13.Phys. abuse, T2 & -.18 & 0.12 & -0.05 & $0.21^{*}$ & 0.03 & .00 & .20 & 0.15 & 0.11 & $0.45^{*}$ & $0.66^{*}$ & $0.41^{*}$ & \\
\hline M & - & 16.38 & 1.63 & 31.68 & 5.54 & $.00^{\mathrm{a}}$ & $.03^{\mathrm{a}}$ & 21.67 & 21.18 & 18.74 & 18.81 & 4.73 & 5.14 \\
\hline SD & - & 1.17 & 9.43 & 7.94 & 3.57 & .83 & .81 & 5.06 & 5.63 & 6.16 & 6.64 & 1.63 & 2.39 \\
\hline
\end{tabular}

Note

IP = interparental; $\mathrm{P}-\mathrm{A}=$ parent-adolescent; Pos. res. = positive resolution.

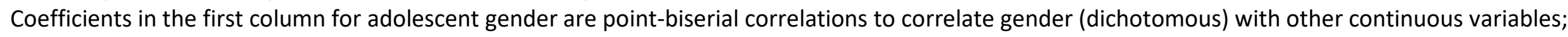
otherwise correlations reported are Pearson's correlations.

aThese variable were the average of two standardized variables, as reflected in the M and SD.

$* p<.05$. 
Adolescent dating relationship behaviors also were correlated such that adolescents who reported more positive conflict resolution behaviors also reported using more verbally abusive tactics with their dating partners. This positive association may reflect an overall higher frequency of dating relationship conflict. Adolescent dating behaviors were stable over time, with correlations that were moderate to large in magnitude ( $r s=.41-.73$ ).

\section{Triangulation and Parent-Adolescent Closeness as Predictors of Adolescent Dating} Relationship Quality

The first set of three hierarchical regression models is summarized in Table 2. The three models (for each outcome-positive conflict resolution, verbal abuse, and physical abuse) are reported in separate columns. In the first model, predicting adolescents' positive conflict resolution behaviors at T2, controlling for T1 levels of positive conflict resolution, age, interparental conflict, and anger regulation, triangulation was associated with increases in adolescents' positive conflict resolution over time ( $b=.29, p<.01$ ), but parent-adolescent closeness was not. In the second block, the multiplicative term for gender and parent-adolescent closeness was statistically significant $(b=.21, p<.05)$. To understand this interaction, we plotted the regression lines separately for boys and girls in Figure 1 . As depicted in this figure, parent-adolescent closeness was positively associated with the use of positive resolution strategies in dating relationships $(b=.41 p<.01)$ for boys. For girls, the association was nonsignificant. 
Table 2. Regressions for Parent-Adolescent Closeness Models

\begin{tabular}{|c|c|c|c|c|c|c|c|c|c|c|}
\hline & & Model 1 & & & Model 2 & & & Model 3 & & \\
\hline & & Positive conflict Resolution T2 & & & Verbal abuse T2 & & & Physical abuse T2 & & \\
\hline Block & Predictors & $\mathrm{b}$ & SE & t-Value & $\mathrm{b}$ & SE & t-Value & $\mathrm{b}$ & SE & t-Value \\
\hline \multirow[t]{9}{*}{1} & Main effect & & & & & & & & & \\
\hline & $\mathrm{R}^{2}$ & & .45 & & & .52 & & & .16 & \\
\hline & T1 DV & $.58^{* *}$ & .08 & 7.34 & $.67^{* *}$ & .07 & 10.36 & $.26 * *$ & .09 & 3.06 \\
\hline & Age & $.26^{*}$ & .10 & 2.56 & .11 & .08 & 1.35 & .11 & .10 & 1.13 \\
\hline & IPC & -.07 & .09 & -0.83 & -.02 & .07 & -0.32 & -.07 & .11 & -0.61 \\
\hline & Anger regulation & -.07 & .08 & -0.93 & .05 & .06 & 0.80 & .17 & .09 & 1.95 \\
\hline & Gender & -.12 & .10 & -1.23 & -.09 & .06 & -1.48 & -.07 & .09 & -0.72 \\
\hline & Tri & $.29 * *$ & .10 & 2.98 & .15 & .08 & 1.83 & .08 & .11 & 0.77 \\
\hline & P-A close & .16 & .09 & 1.79 & .01 & .08 & 0.15 & .04 & .10 & 0.40 \\
\hline \multirow[t]{5}{*}{2} & 2-way interaction & & & & & & & & & \\
\hline & $\mathrm{R}^{2}$ & & .52 & & & .58 & & & .20 & \\
\hline & Tri*Gender & .19 & .10 & 1.91 & -.07 & .07 & -0.93 & -.16 & .10 & -1.61 \\
\hline & P-A close*Gender & $.21^{*}$ & .09 & 2.45 & $-.19 * *$ & .07 & -2.86 & -.06 & .09 & -0.60 \\
\hline & Tri*P-A close & -.17 & .10 & -1.64 & $-.16 *$ & .08 & -2.09 & -.06 & .10 & -0.60 \\
\hline \multirow[t]{3}{*}{3} & 3-way interaction & & & & & & & & & \\
\hline & $\mathrm{R}^{2}$ & & .53 & & & .59 & & & .22 & \\
\hline & Tri*P-A close*Gender & .10 & .09 & 1.22 & -.05 & .07 & -0.62 & .15 & .10 & 1.51 \\
\hline
\end{tabular}

\section{Note}

Tri = triangulation; IPC = interparental conflict; P-A close = parent-adolescent closeness.

Unstandardized coefficients were computed using standardized data and can be interpreted as standardized beta coefficients.

$* p<.05 ; * * p<.01$. 
Predicting verbally abusive dating behavior, after accounting for control variables, there were no statistically significant main effects in the first block. In the second block, two interaction terms were statistically significant. The first, Parent-adolescent closeness* Gender $(b=-.19, p<.01)$, is plotted in Figure 1b. This interaction suggests that in the context of low levels of parent-adolescent closeness, triangulation is related to increases in verbally abusive dating behavior $(b=.48, p<.05)$, but was not related to verbal abuse in the context of high parent-adolescent closeness $(b=-.06, n s)$. The Gender*Parent-adolescent closeness interaction term also was significant $(b=-.16, p<.05$; Figure $1 c)$, in which girls' close relationships with parents were positively correlated with verbally abusive dating relationships ( $b=.14, p=.08$ ) and boys' relationship closeness was negatively correlated with verbally abusive dating behavior $(b=-.21, p=.17)$. It is noteworthy that neither association was statistically significant.

The third regression model was computed to predict physical abuse in dating relationships. None of the models for main effects or interactions were statistically significant, indicating a poor predictive model for physical abuse.

\section{Triangulation and Parent-Adolescent Conflict Predictors of Adolescent Dating Relationship Behaviors}

Analyses conducted for the second aim are summarized in Table 3. Following the same approach as the first aim, these models examined the role of parent-adolescent conflict and triangulation for each of the outcomes. The first model was estimated to predict adolescent's positive conflict resolution behaviors over time. Controlling for T1 positive resolution, interparental conflict, age, and anger regulation, adolescent triangulation was associated with increases in positive conflict resolution $(b=.30, p<.01)$, consistent with prior findings. There were no statistically significant interaction terms in relation to positive conflict resolution. 
Table 3. Regressions for Parent-Adolescent Conflict Models

\begin{tabular}{|c|c|c|c|c|c|c|c|c|c|c|}
\hline & & Model 1 & & & Model 2 & & & Model 3 & & \\
\hline & & Positive conflict Resolution T2 & & & Verbal abuse T2 & & & Physical abuse T2 & & \\
\hline Block & Predictors & $b$ & SE & t-Value & $b$ & SE & t-Value & $\mathrm{b}$ & SE & t-Value \\
\hline \multirow[t]{9}{*}{1} & Main effect & & & & & & & & & \\
\hline & $\mathrm{R}^{2}$ & & .43 & & & .53 & & & .19 & \\
\hline & T1 DV & $.58 * *$ & .09 & 6.64 & $.68^{* *}$ & .07 & 10.12 & $.25 * *$ & .09 & 2.87 \\
\hline & Age & $.23^{*}$ & .10 & 2.42 & .11 & .08 & 1.27 & .10 & .10 & 1.00 \\
\hline & IPC & -.11 & .10 & -1.15 & -.07 & .07 & -0.93 & -.15 & .10 & -1.46 \\
\hline & Anger regulation & -.07 & .09 & -0.87 & .03 & .07 & 0.47 & .14 & .09 & 1.49 \\
\hline & Gender & -.10 & .10 & -1.06 & -.09 & .06 & -1.38 & -.06 & .09 & -0.61 \\
\hline & Tri & $.30 * *$ & .10 & 3.09 & .14 & .08 & 1.73 & .07 & .11 & 0.68 \\
\hline & P-A conflict & & & & & & & & & \\
\hline \multirow[t]{5}{*}{2} & 2-way interaction & & & & & & & & & \\
\hline & $\mathrm{R}^{2}$ & & .46 & & & .57 & & & .22 & \\
\hline & Tri*Gender & .17 & .09 & 1.87 & -.07 & .07 & -1.03 & -.14 & .10 & -1.39 \\
\hline & P-A conflict*Gender & -.14 & .13 & -1.04 & $.20^{*}$ & .09 & 2.24 & .03 & .11 & 0.24 \\
\hline & Tri*P-A conflict & .04 & .11 & 0.36 & .11 & .08 & 1.28 & -.01 & .12 & -0.07 \\
\hline \multirow[t]{3}{*}{3} & 3-way interaction & & & & & & & & .24 & \\
\hline & $\mathrm{R}^{2}$ & & .49 & & & .58 & & & .24 & \\
\hline & Tri*P-A conflict*Gender & -.06 & .10 & -0.61 & -.05 & .09 & -0.60 & $-.19 *$ & .09 & -2.07 \\
\hline
\end{tabular}

\section{Note}

Tri = triangulation; IPC = interparental conflict; P-A conflict = parent-adolescent conflict.

Unstandardized coefficients were computed using standardized data and can be interpreted as standardized beta coefficients.

$* p<.05 ; * * p<.01$. 
The second model was computed to predict verbal abuse at T2. After accounting for T1 verbal abuse, there were no statistically significant main effect predictors. In the second block, there was a statistically significant two-way interaction for parent-adolescent conflict and gender $(b=.20, p<.05)$. As shown in Figure 1d, parent-adolescent conflict was associated with increases in verbally abusive behavior for boys $(b=.29, p=.09)$, but the association was near zero for girls $(b=.01, p=.87)$. The three-way interaction term was not statistically significant.

The third model predicted adolescent physical abuse in dating relationships. After accounting for physical abuse at T1, no other main effect predictors were statistically significant. None of the two-way interaction terms were statistically significant. However, the three-way interaction term, Triangulation*Parent-adolescent conflict*Gender, was statistically significant $(b=-.19, p<.05)$. Probes of this three-way interaction term revealed one unique risk group. For girls in families with high levels of parent-adolescent conflict, triangulation was positively associated with physically abusive dating behaviors ( $b=.61, p=.06)$. No statistically significant associations were found for girls in low-conflict relationships with their parents or for boys (in high or low P-A conflict families). These findings indicate that the combination of parent-adolescent conflict and triangulation reflects a high-risk context for girls' physically abusive behavior in dating relationships.

\section{Discussion}

Guided by a family systems framework, this study examined family processes that may contribute to adolescents' constructive (i.e., positive resolution) and destructive (i.e., verbal and physical abuse) behavior in dating relationships. Toward this end, we examined dyadic (interparental and parent-child relationships) and triadic processes (triangulation) that may impact adolescents' acquisition of conflict resolution skills that promote competence in romantic relationships and maladaptive strategies for resolving disagreements with a dating partner. Using a short-term longitudinal design, we were able to test how these family processes predicted change in dating behaviors over time. Overall, the findings support the value of expanding the conceptualization of family influences that shape interpersonal effectiveness in dating relationships.

Perhaps the most novel aspect of this study was the evaluation of triangulation into parental conflicts as a predictor of adolescents' skill in resolving disagreements with their own dating partners. Interestingly, our results revealed both positive and negative implications of triangulation for adolescent dating relationships. Adolescents who were drawn into parental conflicts reported greater use of verbally abusive conflict tactics, such as belittling, threatening, and antagonizing their dating partners. However, this association was moderated by parent-adolescent closeness. Specifically, the positive association between triangulation and verbal aggression was only upheld for youth who felt emotionally distant (i.e., low in closeness) with their parents; when youth felt close with their parents, triangulation was no longer correlated with verbally abusive behavior with dating partners. This finding complements previous work that documents a longitudinal association in which triangulation is related to decreases in parent-adolescent closeness over time (Fosco \& Grych, [27]). The combination of triangulation and low parent-adolescent closeness may reflect a subgroup of youth living in families with chronic discord. This context may be characterized by scapegoating, a common form of triangulation in which attention is diverted from marital problems to the child's behavior (Buchanan \& Waizenhofer, [9]; Minuchin, [49]). Over time, youth may become reinforced for acting up or yelling at 
parents during conflict episodes if it effectively terminates the interparental disagreements and reroutes attention to them (Davis, Hops, Alpert, \& Sheeber, [23]). It is possible that this process generalizes to dating conflict resolution skills. If verbally aggressive tactics prove effective in stopping parental disagreements, such behavior may also be used in an effort to terminate conflicts in other relationships. Thus, the function of verbally aggressive behavior in the family may transfer to dating relationships as an attempt to resolve the disagreement or to draw attention or engagement from one's partner.

A surprising finding in the current study was that triangulation also was associated with increases in adolescents' use of positive conflict resolution strategies in dating relationships. This association was not moderated by gender, parent-adolescent closeness, or parent-adolescent conflict, indicating a direct association with increases in positive conflict resolution in dating relationships over time. The positive association between triangulation and positive conflict resolution skills may indicate that triangulation may promote some positive conflict resolution skills. It is possible that this positive association is reflective of a different triangulation dynamic - mediation-in which adolescents are drawn into parental conflicts to serve as a mediator who must help both parents reach a place of resolution in their disagreements. For adolescents who become effective mediators of their parents' disputes, they may actually learn constructive approaches to resolving disagreements that they can apply to their own relationships. Some evidence suggests that family dynamics in which diffuse parentadolescent boundaries exist may lead parents to place developmentally inappropriate expectations on their child to provide caregiving, serve as a confidant, and help them cope with stresses in their own lives and relationship with their spouse (Kerig, [42]). Although these boundary problems are generally viewed as detrimental to adolescents' mental health, there may be incidental benefits for adolescents' dating relationships.

A different story emerged for the role of parent-adolescent dyadic relationships and adolescent dating behavior. Findings provided support for our hypotheses that close parent-adolescent relationships would promote more positive conflict resolution and less verbal abuse in dating relationships, just as parent-adolescent conflict would serve as a risk factor that undermines effective conflict resolution and promotes abusive tactics. Consistent with similar studies, findings differed for boys and girls. In this sample, parent-adolescent closeness was related to boys' (but not girls') increases in positive conflict resolution skills. This suggests that close, trusting relationships with parents can help promote effective communication and conflict resolution strategies (Cui \& Conger, [18]; Vieno et al., [65]) and provide the foundation for positive romantic relationships into adulthood. A second interaction was found between closeness with parents and adolescent gender, suggesting that closeness was negatively associated with verbal abuse for boys, but positively associated with verbal abuse for girls. When probed, neither slope for boys and girls was statistically significant, calling for caution in interpreting the current findings until they can be replicated.

Parent-adolescent conflict was implicated in both verbal abuse and physical abuse in dating relationships, but these associations were moderated by gender. In relation to verbal abuse, parentadolescent conflict was a risk factor for boys, but not for girls. These findings, at least for boys, are consistent with the view that parent-adolescent interactions may generalize to other significant relationships (Buehler, [10]; Linder \& Collins, [46]; Meeus et al., [48]). When predicting physical 
aggression, parent-adolescent conflict was a risk factor that differed as a function of triangulation and adolescent gender. In this three-way interaction, a positive correlation emerged between triangulation and physical aggression for girls who experienced high levels of conflict with their parents.

Triangulation may amplify the role of parent-adolescent conflict for girls who find themselves embroiled in hostility across different relationships in the family. Drawing on theory that girls may be more attuned to relationships in the family (Davies \& Lindsay, [20]), it is understandable that the cooccurrence of parent-adolescent conflict and high levels of triangulation would create a context of considerable risk for girls. These findings qualify the ways that adolescents who experience escalating conflicts with their parents may enter dating relationships ill-equipped to manage disagreements effectively.

Different patterns of results were consistently found for boys and girls. Boys' positive conflict resolution skills and verbally abusive behavior were more closely related to their relationships with their parents than girls. On the other hand, girls exhibited higher levels of risk for physically abusive dating behavior in a high-risk family context. This pattern of results is consistent with other studies that also report gender differences in how adolescent-parent attachment may function for adolescents. For example, boys who are insecurely attached tend to have a stronger association between their own maltreatment as a child and later dating abuse (Wekerle \& Wolfe, [67]). In addition, Grych and Kinsfogel ([33]) found unique patterns for adolescents' attachment to their parents in relation to abusive dating behaviors. Boys' exposure to family aggression was related to abusive dating relationship behaviors if they were higher in attachment anxiety. Interestingly, girls were more likely to be physically abusive if they were exposed to higher levels of family aggression (interparental and parent-child hostility) and reported low levels of attachment avoidance. The current study used a measure of parent-adolescent closeness, which consisted of sharing personal feelings with their parents and feeling safe and trusting of their parents' availability. This closeness scale may be more similar to the attachment anxiety scale used by Grych and Kinsfogel ([33]), and it may account for stronger findings for boys in the analyzed sample. For girls, the current findings indicate that parent hostility was qualified by being triangulated into parental conflicts and highlight a more nuanced process by which girls adopt physically abusive behavior.

\section{Limitations and Future Directions}

This study is not without limitations. This study employed a short-term longitudinal design that warrants replication with a long-term follow-up. Further, with longitudinal methods, a common challenge is sample retention. Although we used appropriate methods for handling attrition in this sample, it is nonetheless a limitation. Moreover, this study relied entirely on adolescent self-report, which is vulnerable to possible inflation of estimated associations due to shared method variance. Another possible concern is the presence of teachers during survey administration, which may have led students to under-report problem behavior. Thus, replication and extension with multimethod, multiinformant designs with more extensive follow-up data are needed.

In addition, further study is needed to better understand the current findings that triangulation was related to both increased positive conflict resolution and increased verbal abuse in dating relationships. There may be different patterns of triangulation across families - some that reinforce aggressive behavior and others that promote conflict resolution skills - that should be disentangled. 
The current study drew on a global measure of triangulation that incorporated adolescents' perceptions of being caught in the middle, asked to take sides, or that conflicts were rerouted to them, and consequently did not assess other forms of triangulation.

Finally, in accordance with a family systems framework, other family relationships may contribute to adolescent's dating relationship behaviors. Of particular omission in the current study was the quality of sibling relationships. The inclusion of sibling relationships would provide a more complete picture of the family context in which social-interactional patterns are experienced and would help to better understand the ways in which the family environment shapes adolescents' romantic relationships.

\section{Conclusion}

This study offers a broader conceptualization of the ways that family relationships impact adolescent dating relationships by drawing on dyadic and triadic influences on adolescent dating relationships. Of note, we found that adolescents' triangulation into parental conflicts was consistently associated with both positive and abusive behaviors in dating relationships. Historically, research examining triangulation has underscored this process as a risk factor for maladjustment or poor peer relationships, but the current findings reflect a relative "gray area" in which triangulation may not be entirely harmful; in the context of presenting significant risk for diminished emotional and behavioral well-being, some triangulated adolescents may also learn some effective strategies for managing conflicts with others. We also found that, for boys, close relationships with parents promoted more effective dating relationship behaviors; conversely, parent-adolescent conflict was related to more verbally abusive behaviors. Overall, the pattern of results indicated that triangulation and parentadolescent relationships offer distinct insights into adolescents' competence in navigating their own romantic relationships.

\section{Footnotes}

1 The authors would like to thank the participants and staff at Hamilton High School in Milwaukee, Wisconsin, for their participation in this study. We also would like to thank graduate and undergraduate research assistants who aided in the collection and preparation of these data. Finally, we would like to thank Gabriel L. Schlomer for his assistance with our analyses. Portions of these findings were presented at the Society for Research on Child Development 2013 biennial conference.

\section{References}

Ackard, D. M., Eisenberg, M. E., \& Neumark-Sztainer, D. ( 2007). Long-term impact of adolescent dating violence on the behavioral and psychological health of male and female youth. Journal of Pediatrics, 151, 476 - 481. doi: 10.1016/j.jpeds.2007.04.034

Afifi, T. D., \& Schrodt, P. ( 2003). "Feeling caught" as a mediator of adolescents' and young adults' avoidance and satisfaction with their parents in divorced and non-divorced households. Communication Monographs, 70, $142-173$.

Aikins, J. W., Simon, V. A., \& Prinstein, M. J. ( 2010). Romantic partner selection and socialization of young adolescents' substance use and behavior problems. Journal of Adolescence, 33, 813 826. doi: 10.1016/j.adolescence.2010.07.007

Amato, P. R., \& Afifi, T. D. ( 2006). Feeling caught between parents: Adult children's relations with parents and subjective well-being. Journal of Marriage and the Family, 68, $222-235$. 
Armsden, G. C., \& Greenberg, M. T. ( 1987). The inventory of parent and peer attachment: Individual differences and their relationship to psychological well-being in adolescence. Journal of Youth and Adolescence, 16, $427-454$.

Bell, L. G., Bell, D. C., \& Nakata, Y. ( 2001). Triangulation and adolescent development in the US and Japan. Family Process, 40, $173-186$.

Bickham, N. L., \& Fiese, B. H. ( 1997). Extension of the Children's Perceptions of Interparental Conflict Scale for use with late adolescents. Journal of Family Psychology, 11, $246-250$.

Brown, B. B., Mounts, N., Lamborn, S. D., \& Steinberg, L. ( 1993). Parenting practices and peer group affiliation in adolescence. Child Development, 64, 467-482.

Buchanan, C. M., \& Waizenhofer, R. ( 2001). The impact of interparental conflict on adolescent children: Considerations of family systems and family structure. In A. Booth, A. C. Crouter, \& M. Clements (Eds.), Couples in conflict (pp. 149 - 160). Mahwah, NJ : Lawrence Erlbaum.

Buehler, C. ( 2006). Parents and peers in relation to early adolescent problem behavior. Journal of Marriage and the Family, 68, $109-124$.

Buehler, C., Franck, K. L., \& Cook, E. C. ( 2009). Adolescents' triangulation in marital conflict and peer relations. Journal of Research on Adolescence, 19, 669-689.

Buehler, C., \& Welsh, D. P. ( 2009). A process model of adolescents' triangulation into parents' marital conflict: The role of emotional reactivity. Journal of Family Psychology, 23, $167-180$.

Callahan, M. R., Tolman, R. M., \& Saunders, D. G. ( 2003). Adolescent dating violence victimization and psychological well-being. Journal of Adolescent Research, 18, 664-681.

Collins, W. A., Welsh, D. P., \& Furman, W. ( 2009). Adolescent romantic relationships. Annual Review of Psychology, 60, $631-652$.

Cook, E. C., Buehler, C., \& Blair, B. L. ( 2013). Adolescents' emotional reactivity across relationship contexts. Developmental Psychology, 49, $341-352$.

Cornelius, T. L., \& Resseguie, N. ( 2007). Primary and secondary prevention programs for dating violence: A review of the literature. Aggression and Violent Behavior, 12, $364-375$.

Creasey, G., \& Hesson-Mclnnis, M. ( 2001). Affective responses, cognitive appraisals, and conflict tactics in late adolescent romantic relationships: Associations with attachment orientations. Journal of Counseling Psychology, 48, 85 - 96.

Cui, M., \& Conger, R. D. ( 2008). Parenting behavior as mediator and moderator of the association between marital problems and adolescent maladjustment. Journal of Adolescent Research, 18, $261-284$.

Cummings, E. M., Goeke-Morey, M. C., Papp, L. M., \& Dukewich, T. L. ( 2002). Children's responses to mothers' and fathers' emotionality and tactics in marital conflict in the home. Journal of Family Psychology, 16, $478-492$.

Davies, P. T., \& Lindsay, L. L. ( 2004). Interparental conflict and adolescent adjustment: Why does gender moderate early adolescent vulnerability? Journal of Family Psychology, 18, 160 - 170.

Davies, P. T., \& Windle, M. ( 2000). Middle adolescents' dating pathways and psychosocial adjustment. Merrill-Palmer Quarterly, 46, 90 - 118.

Davila, J., Stroud, C. B., Miller, M. R., \& Steinberg, S. J. ( 2007). Commentary: Defining and understanding adolescent romantic competence: Progress, challenges, and implications. Journal of Clinical Child and Adolescent Psychology, 36, 534- 540.

Davis, B. T., Hops, H., Alpert, A., \& Sheeber, L. ( 1998). Child responses to parental conflict and their effect on adjustment: A study of triadic relations. Journal of Family Psychology, 12, $163-177$.

Dawson, J. F. ( 2014). Interpreting interaction effects. Retrieved October 20, 2014, from http://www.jeremydawson.com/slopes.htm 
Eisenberg, N., Cumberland, A., \& Spinrad, T. L. ( 1998). Parental socialization of emotion. Psychological inquiry, 9, $241-273$.

Fosco, G. M., \& Grych, J. H. ( 2008). Emotional, cognitive, and family systems mediators of children's adjustment to interparental conflict. Journal of Family Psychology, 22, 843-854.

Fosco, G. M., \& Grych, J. H. ( 2010). Adolescent triangulation into parental conflicts: Longitudinal implications for appraisals and adolescent-parent relations. Journal of Marriage and the Family, $72,254-266$.

Foshee, V. A. (1996). Gender differences in adolescent dating abuse prevalence, types, and injuries. Health Education Research, 11, 275 - 286.

Fullinwinder-Bush, N., \& Jacobvitz, D. B. ( 1993). The transition to young adulthood: Generational boundary dissolution and female identity development. Family Process, 32 (1), $87-103$.

Furman, W., \& Collins, W. A. ( 2008). Adolescent romantic relationships and experiences. In K. H. Rubin, W. Bukowski, \& B. Laursen (Eds.), Handbook of peer interactions, relationships, and groups. New York, NY : Guilford Press.

Granic, I., \& Patterson, G. R. ( 2006, January). Toward a comprehensive model of antisocial development: A dynamic systems approach. Psychological Review, 113 (1), $101-131$.

Grusec, J. E. ( 2011). Socialization processes in the family: Social and emotional development. Annual Review of Psychology, 62, $243-269$.

Grych, J. H., \& Kinsfogel, K. ( 2010). Exploring the role of attachment style in the relation between family aggression and abuse in adolescent dating relationships. Journal of Aggression, Maltreatment, and Trauma, 19, $624-640$.

Grych, J. H., Raynor, S. R., \& Fosco, G. M. ( 2004). Family processes that shape the impact of interparental conflict on adolescents. Development and Psychopathology, 16, 649 - 665.

Grych, J. H., Seid, M., \& Fincham, F. D. (1992). Assessing marital conflict from the child's perspective: The Children's Perception of Interparental Conflict scale. Child development, 63, 558-572.

Halberstadt, A. G. ( 1991). Toward an ecology of expressiveness: Family socialization in particular and a model in general. In R. S. Feldman \& B. Rime (Eds.), Fundamentals of nonverbal behavior (pp. 106 - 160). New York, NY : Cambridge University Press.

Hill, N. E., Bromell, L., Tyson, D. F., \& Flint, R. ( 2007). Developmental commentary: Ecological perspectives on parental influences during adolescence. Journal of Clinical Child and Adolescent Psychology, 36, $367-377$.

Jacobvitz, D. B., \& Bush, N. F. ( 1996). Reconstructions of family relationships: Parent-child alliances, personal distress, and self-esteem. Developmental Psychology, 32, $732-743$.

Jacobvitz, D., \& Hazen, C. ( 1999). Developmental pathways from infant disorganization to childhood peer relationships. In J. Solomon \& C. George (Eds.), Attachment disorganization (pp. 127 159). New York, NY : Guilford Press.

Jouriles, E. N., McDonald, R., Garrido, E., Rosenfield, D., \& Brown, A. ( 2005). Assessing aggression in adolescent romantic relationships: Can we do it better? Psychological Assessment, 17, 469 475. doi: 10.1037/1040-3590.17.4.469

Jouriles, E. N., McDonald, R., Mueller, V., \& Grych, J. H. ( 2012). Youth experiences of family violence and teen dating violence perpetration: Cognitive and emotional mediators. Clinical Child and Family Psychology Review, 15 ( 1), 58 - 68.

Kerig, P. K. ( 2005). Revisiting the construct of boundary dissolution: A multidimensional perspective. Journal of Emotional Abuse, 5, 5-42. 
Kinsfogel, K. M., \& Grych, J. H. ( 2004). Interparental conflict and adolescent dating relationships: Integrating cognitive, emotional, and peer influences. Journal of Family Psychology, 18, 505 515.

Leon, K., Wallace, T., \& Rudy, D. ( 2007). Representations of parent-child alliances in children's family drawings. Social Development, 16, $440-459$.

Lindahl, K. M. ( 1998). Family process variables and children's disruptive behavior problems. Journal of Family Psychology, 12, 420 - 436. doi: 10.1037/0893-3200.12.3.420

Linder, J. H., \& Collins, W. A. ( 2005). Parent and peer predictors of physical aggression and conflict management in romantic relationships in early adulthood. Journal of Family Psychology, 19, 252 $-262$.

McKinney, C., \& Renk, K. ( 2008). Multivariate models of parent-late adolescent gender dyads: The importance of parenting processes in predicting adjustment. Child Psychiatry and Human Development, 39, $147-170$.

Meeus, W., Branje, S., Van Der Valk, I., \& de Wied, M. ( 2007). Relationships with intimate partner, best friends, and parents in adolescence and early adulthood: A study of the saliency of the intimate partnership. International Journal of Behavior and Development, 31, 449-460.

Minuchin, S. ( 1974). Families and family therapy. Cambridge, MA : Harvard University Press.

Minuchin, P. ( 1985). Families and individual development: Provocations from the field of family therapy. Child Development, 56, $289-302$.

O'Leary, K. D., Smith Slep, A. M., Avery-Leaf, S., \& Cascardi, M. ( 2008). Gender differences in dating aggression among multiethnic high school students. Journal of Adolescent Health, 42, $473-$ 479. doi: 10.1016/j.jadohealth.2007.09.012

Patterson, G. R. ( 1982). Coercive family processes. Eugene, OR : Castalia.

Patterson, G. R., DeBaryshe, B. D., \& Ramsey, E. ( 1989). A developmental perspective on antisocial behavior. American psychologist, 44, $329-335$.

Patterson, G. R., Reid, J. B., \& Dishion, T. J. ( 1992). Antisocial boys ( 4th ed.). Eugene, OR : Castalia. SAS Institute, Inc. ( 2011). SAS/STAT 9.3 user's guide. Cary, NC : Author.

Scaramella, L. V., Rand, D., Conger, R. D., Spoth, R., \& Simons, R. L. ( 2002). Evaluation of a social contextual model of delinquency: A cross-study replication. Child Development, 73, 175 - 195.

Schlomer, G. L., Bauman, S., \& Card, N. A. ( 2010). Best practices for missing data management in counseling psychology. Journal of Counseling Psychology, 57 ( 1), $1-10$.

Seiffge-Krenke, I. ( 2003). Testing theories of romantic development from adolescence to young adulthood: Evidence of a developmental sequence. International Journal of Behavioral Development, 27, 519-531.

Simon, V. A., Aikins, J. W., \& Prinstein, M. J. ( 2008). Romantic partner selection and socialization during early adolescence. Child Development, 79, $1676-1692$.

Simons, R. L., Chao, W., Conger, R. D., \& Elder, G. H. ( 2001). Quality of parenting as mediator of the effect of childhood deviance on adolescent friendship choices and delinquency: A growth curve analysis. Journal of Marriage and the Family, 63, 63 - 79.

Simpson, J. A., Collins, W. A., Tran, S., \& Haydon, K. C. ( 2007). Attachment and the experience and expression of emotions in relationships: A developmental perspective. Journal of Personality and Social Psychology, 72, $355-367$.

Spielberger, C. D., Jacobs, G., Russell, S., \& Crane, R. S. ( 1983). Assessment of anger: The State-Trait Anger scale. Advances in Personality Assessment, 2, 159 - 187.

Straus, M. A. (1979). Measuring intrafamily conflict and violence: The conflict tactics (CT) scales. Journal of Marriage and the Family, 41, $75-88$. 
Tuval-Mashiach, R., \& Shulman, S. ( 2006). Resolution of disagreements between romantic partners among adolescents and young adults: Qualitative analysis of interaction discourses. Journal of Research on Adolescence, 16, 561 - 588.

Vieno, A., Nation, M., Pastore, M., \& Santinello, M. ( 2009). Parenting and antisocial behavior: A model of the relationship between adolescent self-disclosure, parental closeness, parental control, and adolescent antisocial behavior. Developmental Psychology, 45, $1509-1519$.

Wang, L., \& Crane, D. R. ( 2001). The relationship between marital satisfaction, marital stability, nuclear family triangulation, and childhood depression. American Journal of Family Therapy, 29, $337-347$.

Wekerle, C., \& Wolfe, D. A. (1998). The role of child maltreatment and attachment style in adolescent relationship violence. Development and Psychopathology, 10, $571-586$.

Widaman, K. F. ( 2006). Missing data: What to do with or without them. Monographs of the Society for Research in Child Development, 71 (3), $42-64$.

Wolfe, D. A., Scott, K., Reitzel-Jaffe, D., Wekerle, C., Grasley, C., \& Straatman, A.-L. ( 2001). Development and validation of the Conflict in Adolescent Dating Relationships Inventory. Psychological Assessment, 13, 277 - 293. 